\title{
Development of Segregation Etch Print Method and Its Application to Investigation of CC Slab Segregation*
}

\author{
By Ko MIYAMURA,** Shin-ya KITAMURA,** Shoichi SAKAGUCHI,*** \\ Chiyokatsu HAMAGUCHI*** and Masazumi HIRAI**
}

\author{
Synopsis \\ The segregation etch print (EP) method is a new method for detecting \\ and recording segregation in low $\mathrm{S}$ and $\mathrm{Ca}$ added steels. This EP \\ method can rapidly and conveniently detect segregation over a wide area \\ with high resolving power. When EP was applied to CC slab, a coarse \\ network structure was found in the equiaxed crystal zone, which could not \\ be seen by the ordinary etching method for detecting the solidification struc- \\ ture. It was found that the fineness of the network structure was related \\ to the segregation level and the fine structure remarkably suppressed not \\ only central segregation but also $V$-shape segregation. Furthermore, the \\ following casting conditions were considered to be important for making \\ the network structure fine. \\ 1) Low casting velocity \\ 2) Low casting temperature \\ 3) Strong spray cooling \\ 4) Addition of REM \\ 5) Reduced thickness of slab
}

\section{Preface}

Low $\mathrm{S}$ and $\mathrm{Ca}$ added steels feature the low-temperature ductility and the good lamellartearing and hydrogen induced cracking resistance. With progress in the techniques to produce high-purity steels and suppress central segregation in CG slabs, such high-quality steels have gradually been produced by the continuous casting (CG) process. For the detection of segregation, the ordinary methods cannot be applied to these steels, because the rather fine segregation spots of $\mathrm{Mn}$ and $\mathrm{P}$ come into question. In other words, the sulphur print method, which is widely and conveniently used, cannot detect the segregation in these low $\mathrm{S}$ and $\mathrm{Ca}$ added steels, and the etching method by warm $\mathrm{HCl}$ solution cannot precisely evaluate the fine segregation spot.

So the authors set out to develop a new method for the evaluation of segregation in low $\mathrm{S}$ and $\mathrm{Ca}$ added steels, and we have established the segregation etch print (EP) method. This EP method is rapid and as convenient as the sulphur print method. It can detect and record the segregation in a wide area of CG slabs. Moreover, EP has high resolving power to detect fine spot-like segregation as well as central segregation.

On account of its high resolving power, when EP was applied to detect segregation in CG slabs, a network solidification structure, which could not be seen by the ordinary etching method, was observed in the equiaxed crystal zone and it was found that the fineness of this network structure was closely related with the segregation of $\mathrm{CG}$ slabs.

\section{Method and Characteristics of Segregation Etch Print ${ }^{1)}$}

\section{Method}

The procedure of EP method is shown in Fig. 1. At first, the cross section of CG slab is ground to the same fineness as that for sulphur print method. Over the ground surface which is levelled, picric acid solution (composition is shown in Table 1) is poured and the surface is etched for about $30 \mathrm{~min}$ at ambient temperature. With this etching procedure, the segregated region is preferentially etched and the appearance of dendritic structure can be suppressed. The etched surface is then washed by water and dried by warm air. After the special surface treatment to adhere the fine particles in the etch pits, the etched surface is polished by fine polishing paper again. The polishing medium is No. 1000 Emery polishing paper. After this process, fine steel particles, formed by the final polishing process, are filled into the etch pits. When transparent adhesive tape is placed on the surface, these powders adhere to the tape, and when this tape is placed on white paper, the segregation pattern appears as black spots. An example of EP applied to the cross section of CG slab is shown

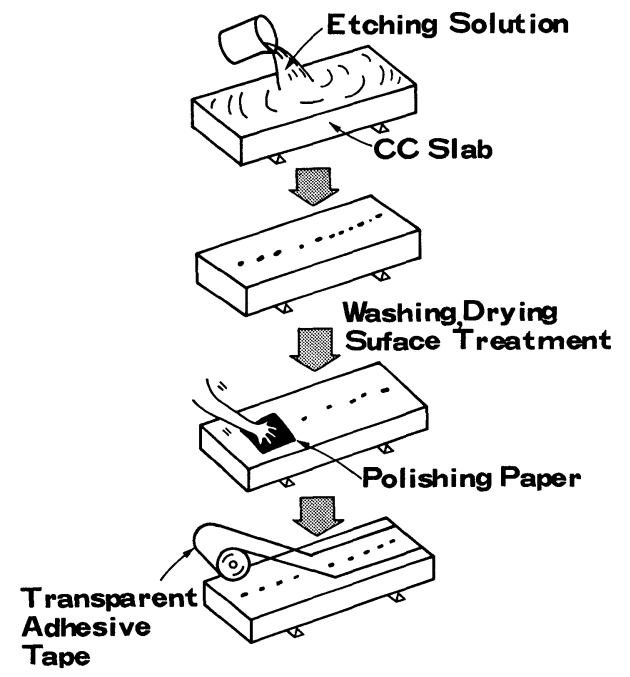

Fig. 1. Procedure of segregation etch print.

Table 1. Composition of etching solution.

\begin{tabular}{cccc}
\hline Picric acid & $\mathrm{CuCl}_{2}$ & Surfactant & Water \\
\hline $60 \mathrm{~g}$ & $15 \mathrm{~g}$ & $60 \mathrm{cc}$ & $3000 \mathrm{cc}$ \\
\hline
\end{tabular}

* Received October 20,1984. (C) 1984 ISIJ

** Yawata R \& D Laboratory, Central R \& D Bureau, Nippon Steel Corporation, Edamitsu, Yahatahigashi-ku, Kitakyushu 805

*** Steelmaking Division, Yawata Works, Nippon Steel Corporation, Edamitsu, Yahatahigashi-ku, Kitakyushu 805. 
in Photo. 1. Although the sulphur content in this steel is about $0.002 \%$ and $\mathrm{Ca}$ is added, segregation can be clearly observed.

\section{Characteristics}

In Photo. 2, EP is compared with another method for resolving power by the same specimen. In the sulphur print method, segregation cannot be detected because $\mathrm{MnS}$ is converted into $\mathrm{CaS}$ by the addition of Ca. In the picture of the segregation image by warm $\mathrm{HCl}$ etchant, the segregation spots can be recognized but they are dim and loose. The same etchant shows poor resolving power also in a photograph of the same etched surface as EP. On the contrary, in the EP method, even fine spot-like segregations can be detected easily with very good contrast. A result of checking the reproducibility of EP is shown in Photo. 3. It is found from this picture that even fairly small segregation spots can be detected with excellent reproducibility. In addition to these features, if the specimen is etched for about $1 \mathrm{hr}$ by warm solution of the same composition, EP can detect the dendritic solidification structure as shown in Photo. 4, and it can detect fine cracks that cannot be easily detected by sulphur print (Photo. 5) or other methods. These characteristics of EP are summarized in Table 2 compared with other methods. It is obvious that EP can detect the segregation and so on, over a wide area of $\mathrm{GG}$ slab rapidly and conveniently with high resolving power.

\section{Relation between EP Image and Solute Segregation}

The segregation image by EP is considered to correlate to the segregation of solute such as $\mathrm{Mn}$ and $\mathrm{P}$. As a result of many trials, it was found that the difference of EP image is unrelated with the average Mn content in ladle analysis. On the other hand, the $\mathrm{P}$ content of steel, even at such a low level as $20 \mathrm{ppm}$, was found to permit easy detection of segregation by the EP method. Therefore, EP image is considered to have a relation with the relative concentration difference of a solute between the segregated area and the matrix, rather than with the average concentration in the specimen.

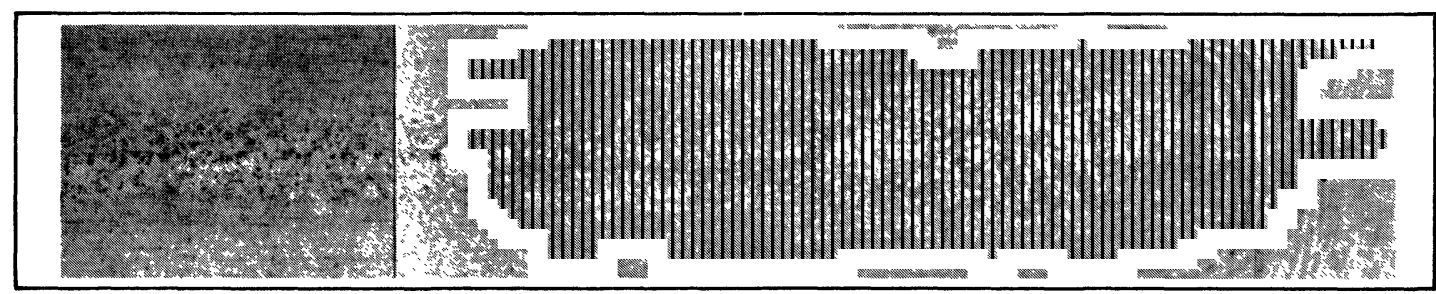

$50 \mathrm{~mm}$

Photo. 1. Example of EP applied to the cross section of GG slab.

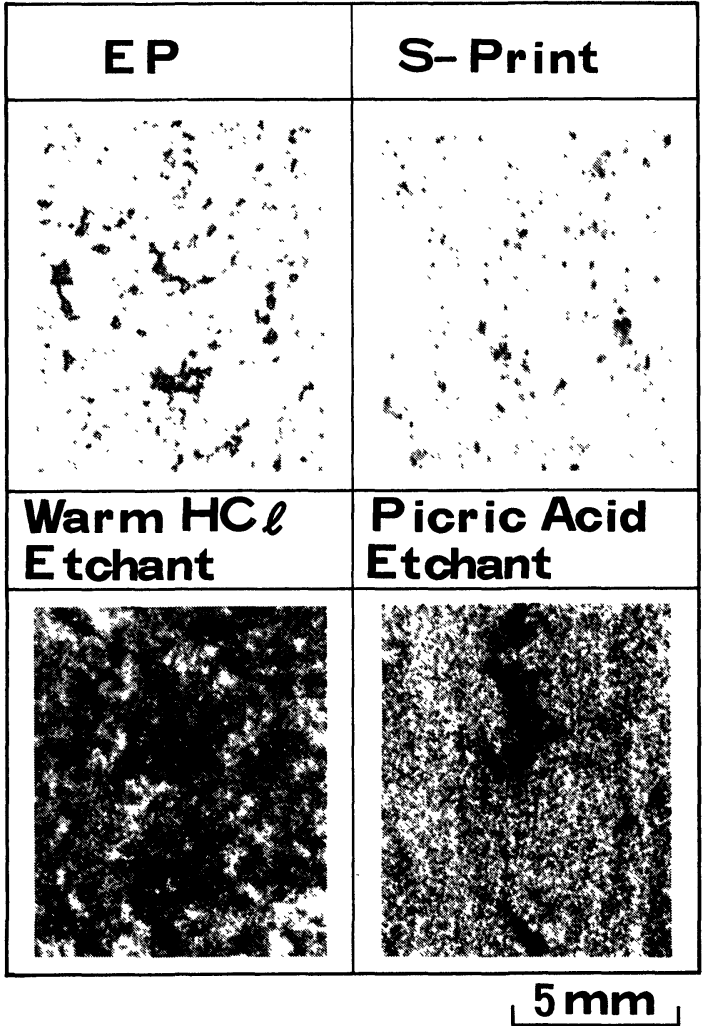

Photo. 2. Comparison of EP and ordinary methods to detect segregation and their resolving power.
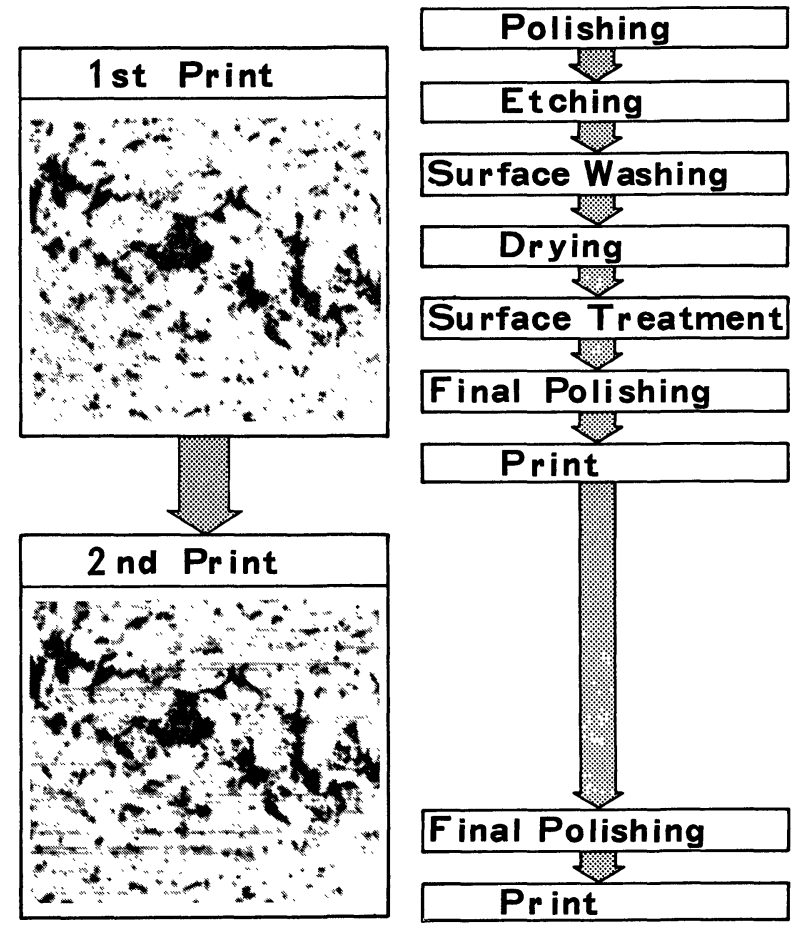

Photo. 3. Result of investigation to confirm the reproducibility of EP. 
Then, in order to investigate the ability of EP to quantify solute segregation, the specimen which was already detected by EP was analysed by macroanalyser (MA). ${ }^{2} \quad$ MA is an analysing apparatus that can locate the segregated region of large and irregular specimens in a short time, using the same principle as the electron probe microanalyser. In this investigation the distribution of $\mathrm{Mn}$ was analysed with an electron beam diameter of $100 \mu \mathrm{m}$. The specimen was cut from CG slab and the size of the analysed area was $50 \mathrm{~mm}$ square. One side of this analysed square was parallel to the central segregation line.

Typical result of comparison of EP and MA images for the same specimen is shown in Photo. 6. In the MA image, the white spot is the segregated region of Mn above some threshold $\mathrm{Mn}$ concentration. In this case, 1.2 times, 1.3 times and 1.4 times the average Mn concentration are defined as the threshold level. From this picture, EP is considered to have a corre-

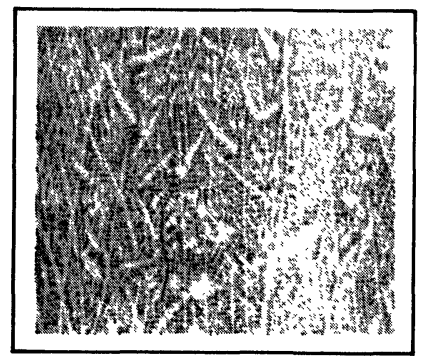

$10 \mathrm{~mm}$

Photo. 4. Example of solidification structure detection by EP.

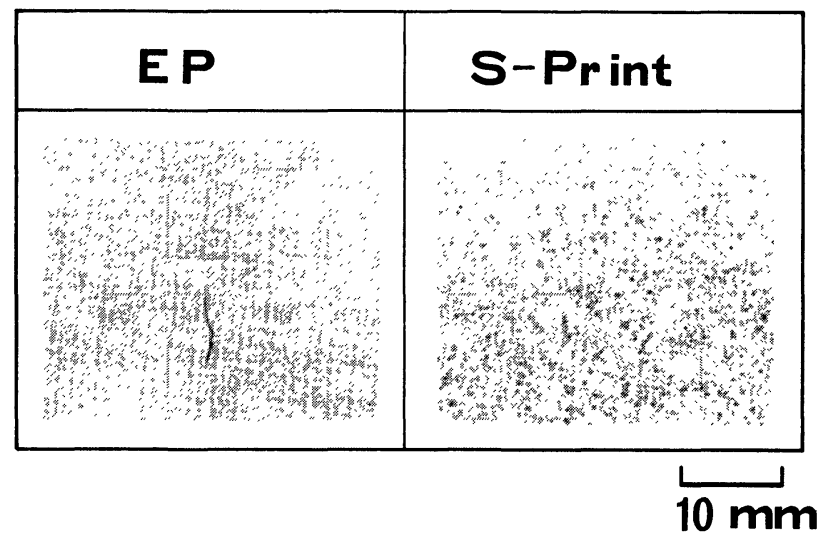

Photo. 5. Example of fine crack detection by EP that can not be found by sulphur print in the same specimen. spondence with the MA image which shows Mn segregation over 1.3 times the average concentration. Comparisons of the segregation spot size detected by EP and MA are shown in Fig. 2 for four typical segregation spots. In this figure, the relation be-

Table 2. Characteristics of EP compared with other methods for detection of segregation.

\begin{tabular}{|c|c|c|c|c|}
\hline & \multicolumn{2}{|l|}{ S-print } & $\begin{array}{c}\text { Warm } \mathrm{HGl} \\
\text { etchant }\end{array}$ & EP \\
\hline $\begin{array}{l}\text { Applicable } \\
\text { steel }\end{array}$ & $\begin{array}{l}\text { Ca treated } \\
\text { Low } \mathrm{S}\end{array}$ & $\frac{x}{\Delta}$ & $\mathrm{O}$ & 0 \\
\hline $\begin{array}{l}\text { Resolving } \\
\text { power }\end{array}$ & 0 & & $x$ & ()) \\
\hline $\begin{array}{l}\text { Operation } \\
\text { time and } \\
\text { environment }\end{array}$ & $\begin{array}{c}90 \mathrm{~min} \\
- \\
\text { (O) }\end{array}$ & & $\begin{array}{c}150 \mathrm{~min} \\
\times\end{array}$ & $\begin{array}{c}90 \mathrm{~min} \\
\mathrm{O}\end{array}$ \\
\hline $\begin{array}{l}\text { Detecting } \\
\text { ability }\end{array}$ & $\begin{array}{l}\text { Segregation } \\
\text { of } \mathrm{S}\end{array}$ & & $\begin{array}{l}\text { Segregation } \\
\text { of } \mathrm{C}\end{array}$ & $\begin{array}{l}\text { Segregation } \\
\text { of } \mathrm{P} \text {, } \\
\text { Mn+Fine } \\
\text { crack }\end{array}$ \\
\hline $\begin{array}{l}\text { Quantitative } \\
\text { analysis }\end{array}$ & $\begin{array}{l}\text { Ca treated } \\
\text { Low } \mathrm{S}\end{array}$ & $x$ & $\begin{array}{c}\text { Overestimate } \\
\triangle\end{array}$ & $\begin{array}{c}\text { Sharp image } \\
\text { (O) }\end{array}$ \\
\hline
\end{tabular}

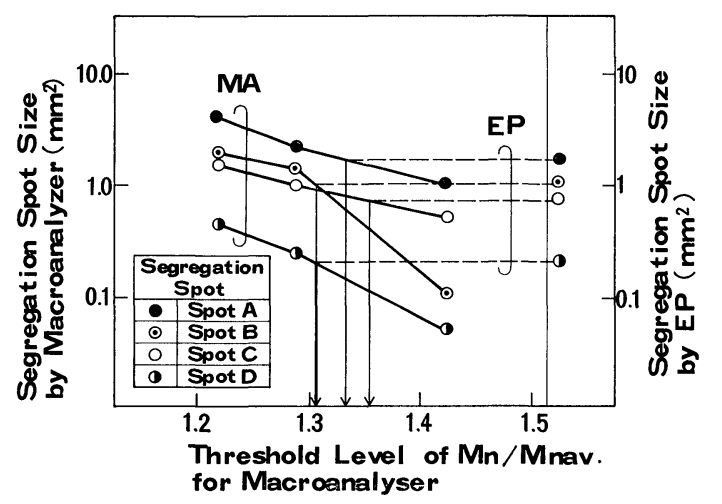

Fig. 2. Comparison of segregation spot size measured in EP and MA images of various threshold Mn levels.

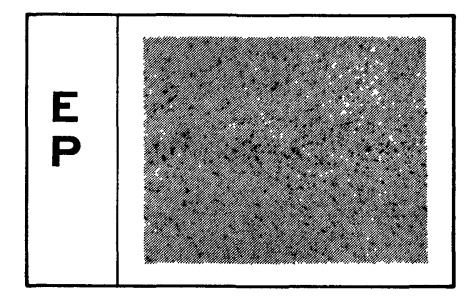

$10 \mathrm{~mm}$

Photo. 6.

Comparison of EP and MA for the distribution of $\mathrm{Mn}$ segregated region.

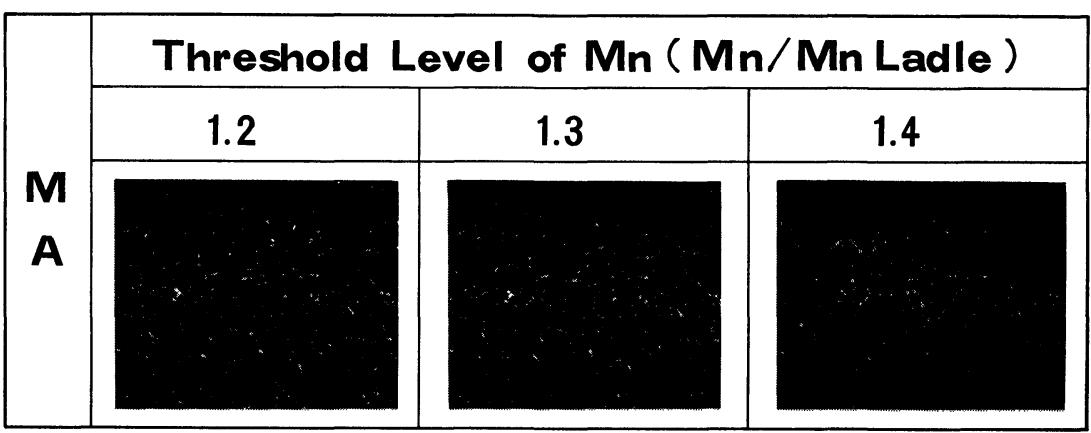


tween the spot size observed by MA and the threshold level is indicated by solid line and the horizontal dotted line is the spot size observed by EP. It is seen that each size of the segregation spot in EP is nearly the same size as that measured by MA where the threshold level is about 1.30 times or 1.35 times the average $\mathrm{Mn}$ concentration.

\section{Application of Segregation Etch Print to the Investigation of Segregation in CC Slab ${ }^{3)}$}

\section{Observation of Network Structure}

As already mentioned, EP can detect the segregated area where the Mn content is about 1.3 times or more the average value, and can evaluate the size and the shape of segregation spot. When this EP method was applied to investigate the segregation of $\mathrm{CC}$ slabs, coarse network solidification structure was observed as shown in Photo. 7. This kind of network structure could hardly be found by the ordinary etching method for observing the solidification structure, e.g., Oberhoffer solution. The size of this network structure, which is defined as the average diameter of each network grain, is related to the thickness of the slab and casting conditions. In some cases, it was clearly detected over the whole equiaxed crystal zone, but in other cases it was hardly observed (Photo. 8). Its maximum size varies from 2 to $5 \mathrm{~mm}$, and its shape is polygonal.

With the ordinary method for detecting the solidification structure, it was found that this network structure consists of many fine crystals (Photo. 9) and that the size of these fine crystals does not change even when the network structure changes its size. From Photo. 9, it was found that only the especially black region of deep and wide etched pits appears in EP

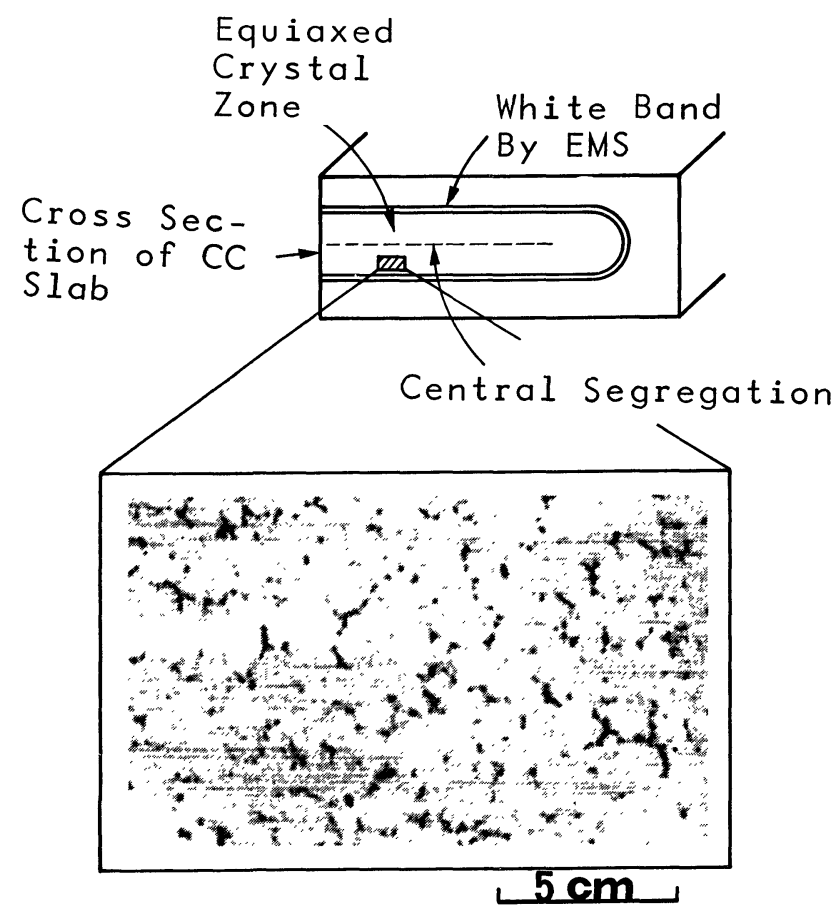

Photo. 7. Example of network structure in the equiaxed crystal zone of CG slab. and that the network structure consists of these black regions.

In addition to these points, the network structure near the center of the slab was less coarse than that near the white band as shown in Fig. 3.

As shown in Photo. 10, the distribution of the Mn segregated region was analysed computer-aided microanalyser (CMA) ${ }^{4)}$ in the equiaxed crystal zone, where the $\mathrm{Mn}$ concentration is 1.3 times or more the average value. The analytical principle of CMA is the same as that of ordinary EPMA, but with the aid of a computer, CMA can analyse the spacious solute distribution accurately and quickly. In Photo. 10, the electron beam diameter is $20 \mu \mathrm{m}$ and the size of the analysed area is $10 \mathrm{~mm}$ square. In comparison with the EP image of the same specimen, this picture shows that the network structure that is seen in EP can be also found in CMA image clearly. In the low Mn

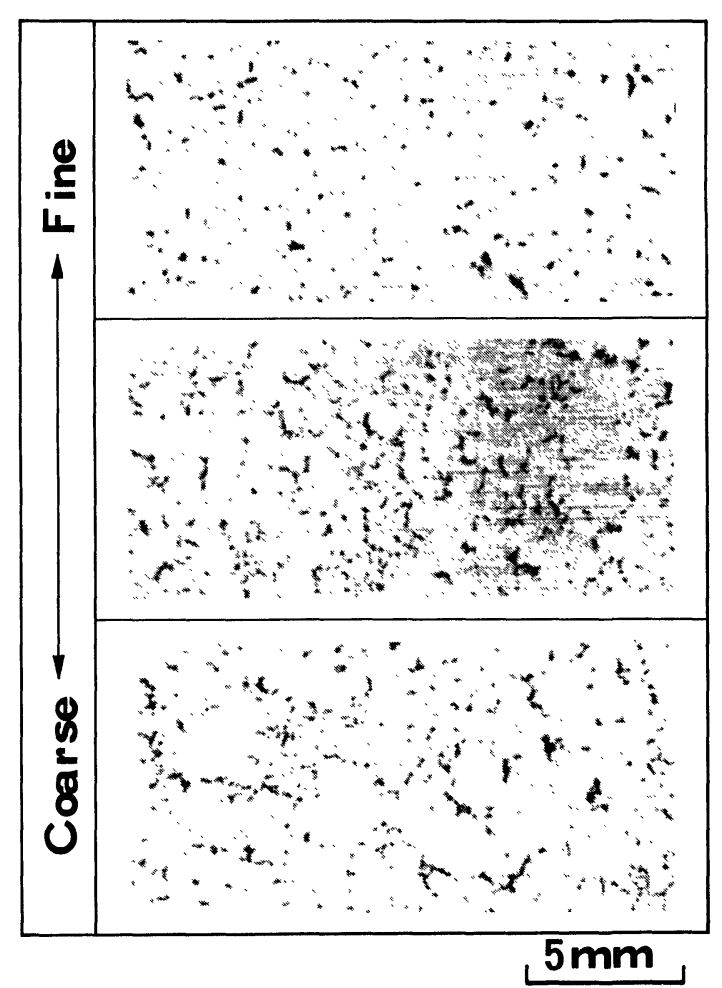

Photo. 8. Typical network structures of various fineness.

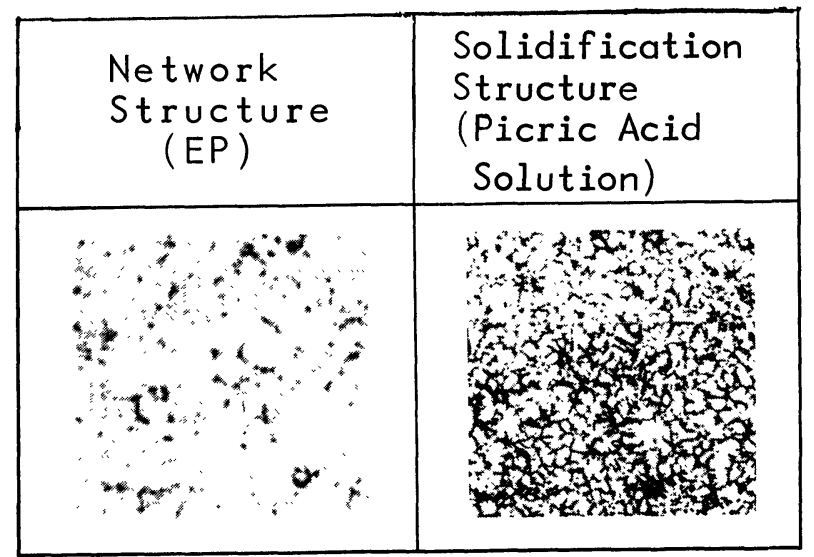

Photo. 9. Comparison of network structure in EP and the solidification structure of the same specimen. 


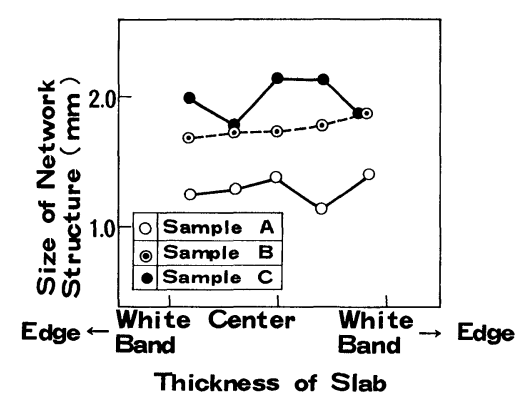

Fig. 3. Size distribution of the network structure.
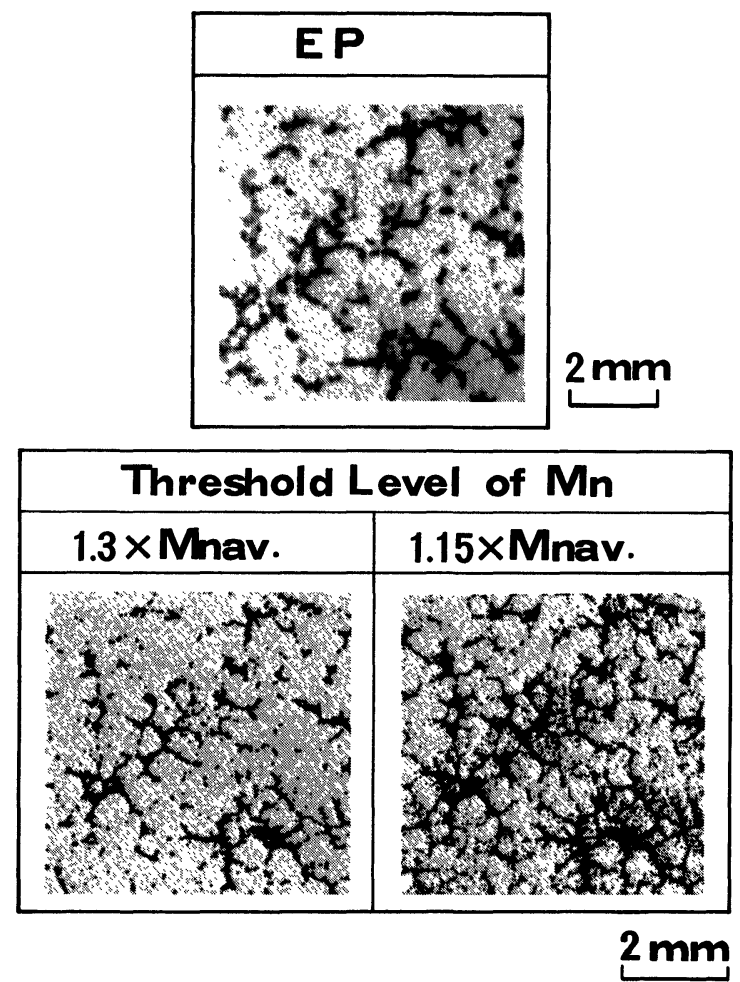

Photo. 10. Comparison of typical network structures in EP with distribution of $\mathrm{Mn}$ segregated region analysed by GMA.

threshold level of 1.15 times the average value, it can be seen that network structures are divided in some small petal-like parts with their roots close to the centre of each network structure.

\section{Relation between Segregation and Network Structure ${ }^{5)}$}

To investigate the relation between the fineness of the network structure and segregation, many experiments were carried out at the vertical type CG machine of No. 1 steelmaking plant of Yawata Works. The cross sections of slabs cast under various conditions were inspected by EP and the segregation level was evaluated corresponding to the maximum size of the segregation spots. In these experiments, electromagnetic stirring (EMS) was applied with the same intensity to all samples.

Figure 4 shows the relation between the central segregation level and the width of equiaxed crystal zone measured by the ordinary method for segregation. For the specimens that were cast at the same casting speed, central segregation was suppressed

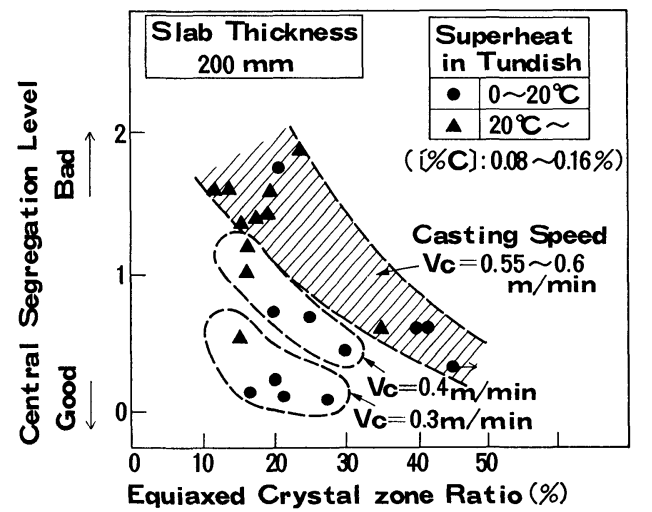

Fig. 4. Relation between the central segregation level and the equiaxed crystal zone ratio.

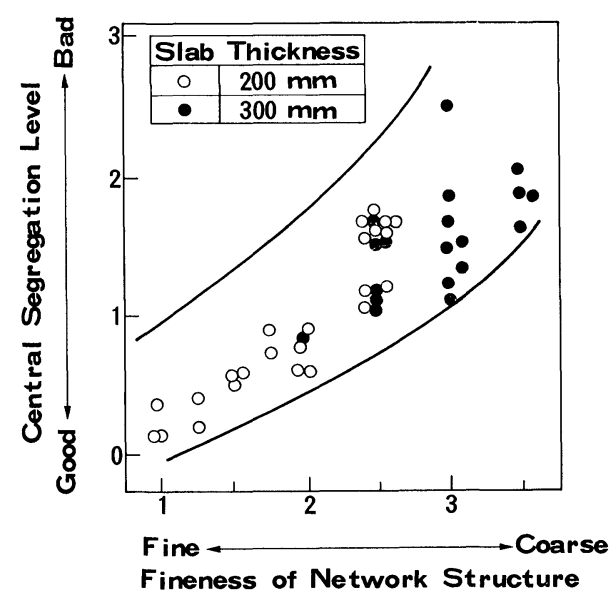

Fig. 5. Relation between the central segregation level and the fineness of network structure.

gradually as the width of equiaxed crystal zone increased. When the casting speed was low, the equiaxed crystal zone was narrow, but the central segregation level was good. This indicates that the width of the equiaxed crystal zone is not the predominant factor for central segregation.

On the contrary, irrespective of casting conditions, the relationship between the level of central segregation and the fineness of the network structure is shown in Fig. 5. From this figure, the fineness of the network structure is considered to be the predominant factor for suppressing central segregation.

In addition to the central segregation, fairly large segregation spots in equiaxed crystal zone (which correspond to $\mathrm{V}$-shape segregation in the sectional view) were found in many cases, and the reduction of such segregation is prerequisite for the production of high-quality steels. Figure 6 shows the relation between the spot segregation level which appears in the central region of the slab (called the dispersed spot segregation level depending on the spot size) and the width of equiaxed crystal zone. In this figure, marking is made according to the fineness of the network structure. In the case of a coarse network structure, as the equiaxed crystal zone widens, the dispersed segregation level becomes worse. On the other hand, when the network structure is fine, the dispersed spot segregation is reduced irrespective 


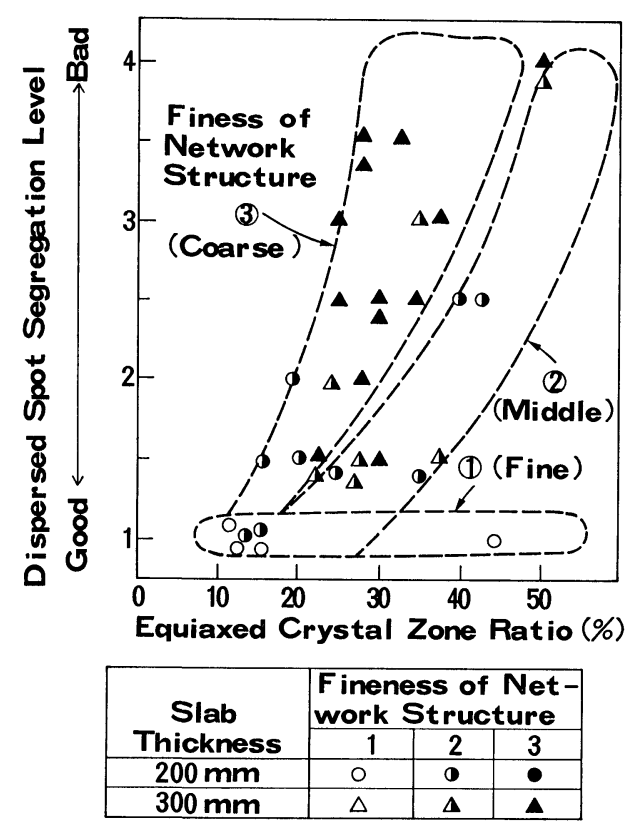

Fig. 6. Relation between dispersed segregation level and the width of equiaxed crystal zone.

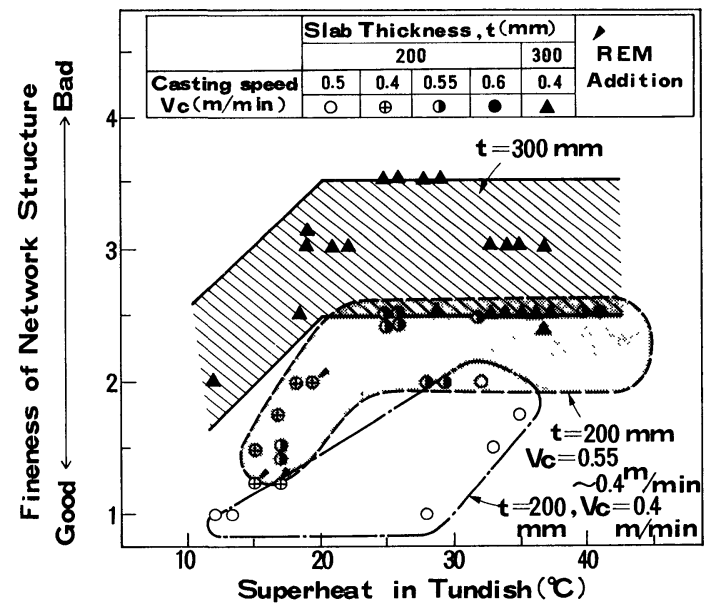

Fig. 7. Casting conditions that affect the fineness of network structure.

of the width of equiaxed crystal zone.

\section{Factors Affecting the Refinement of Network Structure}

The relation between the fineness of network structure and the casting conditions is summarized in Fig. 7. For slabs of equal thickness cast at the same speed, it was found that the network structure became fine as the superheat of molten steel in the tundish dropped below $20^{\circ} \mathrm{C}$. For the slabs of the same thickness and same superheat in the tundish, the slower the casting speed, the finer the network structure. Besides, REM addition to the molten steel (' mark in Fig. 7) prevented the coarsening. Although the results are not given in this figure, when the secondary spray cooling water consumption was increased, the network structure became fine. On the other hand, the network structure of thick slab was coarser than that of thin slab under the same casting conditions.

\section{Discussion}

The following three points were clarified from this experiment.

(1) The network structure has a petal-like form radiating from the centre of each grain.

(2) The network structure near the central region of the slab is less coarse than that near the white band brought about by EMS.

(3) Thick segregated region is found only at the boundary of network structures.

So, these network structures can be considered as separated solid phases, which grow at the solidification front from each independent nucleus in the liquid pool, suspended in the residual liquid phase in the last period of solidification. In other words, each grain which composes the network structure can be considered to be an equiaxed crystal. In Photo. 9, many fine crystals in the grain can be considered as the dendrite arms in the equiaxed crystal. From this point of view, the reason why the fineness of the network structure affects the segregation of CG slab can be considered as follows. If the network structures are fine, they can move together with the residual liquid phase, suppressing the suction flow, when the suction by the solidification shrinkage and bulging takes place. On the other hand, if the network structures are coarse, residual liquid moves easily through the gaps between solid phases, as they cannot move together with the residual liquid phase, and thus the enriched liquid steel causes the V-shape segregation and large spot-like segregation.

As already mentioned, the coarseness of these network structures is influenced by the following casting conditions :

a) Casting speed

b) Casting temperature

c) Addition of REM

d) Secondary spray cooling water amount

e) Slab thickness.

In general, the formation mechanism of equiaxed crystals by EMS is considered as the generation of the nucleus by the melting-off or mechanical breakingoff of the dendrite tips. ${ }^{6,7)}$ It is also believed that the superheat of molten steel has to be lower to keep the nucleus stable. ${ }^{8)}$ These indicate that the formation of stable nuclei is important for making equiaxed crystals fine. Regarding these points, the casting temperature in the present experiments can be considered to have an effect on the number of stable nuclei, and the REM addition is also considered to affect stable nucleation, because it is widely known that the nucleation is promoted by the addition of REM. ${ }^{9,10)}$

On the other hand, low casting speed and strong secondary spray cooling are generally considered to be effective for reducing bulging through the increase of shell stiffness. ${ }^{11)}$ From the results of this experiment, the two factors are now known also to have the effect of making the network structures fine.

The reasons why the size of network structure was affected by the casting speed, secondary spray cooling water amount and slab thickness are presumed to be 
the following.

As already mentioned, the network structure can be considered to be an individual solid phase, which grows at the solidification front from each nucleus in the liquid pool. So the fineness of the network structure is thought to be determined by the number of nuclei in unit volume of the residual liquid phase $(\mathcal{N})$, and $\mathcal{N}$ can be written as the following equation.

$$
\mathcal{N}=\dot{\mathcal{N}} / V
$$

In Eq. (1), $\dot{\mathcal{N}}$ is the nuclei generation rate in the region stirred by EMS, and $V$ is the volumetric velocity of molten metal passing through the EMSstirred region.

$\dot{\mathcal{N}}$ is in proportion to the product of the nuclei generation rate per unit area of solid-liquid interface in the stirred region $(\dot{n})$ and the area of stirred interface $(S)$, because it can be assumed that the nucleation occurs only in the region of strong metal flow generated by EMS.

$$
\dot{\mathcal{N}} \propto \dot{n} \cdot S
$$

If the cross section of the slab at the position of EMS and the length of stirred region can be written as shown in Fig. 8, $S$ can be expressed by Eq. (3).

$$
S=2 L\left\{\left(D_{s}-2 X\right)+\left(D_{l}-2 X\right)\right\}
$$

On the other hand, when the stirring by EMS and the superheat of molten metal are nearly constant, $\dot{n}$ is presumed to be in proportion to the number of dendrite tips. As the number of dendrite tips is in inverse proportion to the square of the primary dendrite arm spacing $(\lambda)$, the following equation can be written.

$$
\dot{n} \propto \lambda^{-2}
$$

Some investigations ${ }^{2}$ ) show that the relation between $\lambda$ and solidification velocity $(\dot{X})$ can be expressed as the following equation.

$$
\lambda \propto \dot{X}^{-0.5}
$$

Because $X$ is generally expressed by Eq. (6), the relation between $\dot{n}$ and $X$ can be written as Eq. (7) where $t$ is the solidification time and $K$ is the solidification constant.

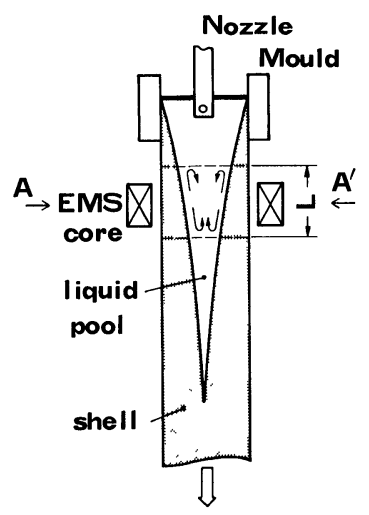

\section{Cross Section $A A^{\prime}$}

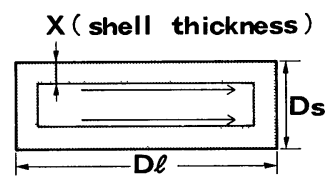

Fig. 8. Geometry of slab.

$$
\begin{aligned}
& X=K \sqrt{ } t \ldots \\
& \dot{n} \propto \dot{X}=K^{2} / 2 X
\end{aligned}
$$

Geometrically, $V$ in Eq. (1) can be regarded as a function of casting speed $\left(V_{c}\right)$ and expressed as follows:

$$
V=\left(D_{s}-2 X\right) \cdot\left(D_{l}-2 X\right) \cdot V_{c}
$$

From substitution of Eqs. (2), (3), (7) and (8) into Eq. (1), $\mathcal{N}$ can be expressed by Eq. (9).

$$
\mathcal{N} \propto \frac{2 L\left\{\left(D_{s}-2 X\right)+\left(D_{l}-2 X\right)\right\}}{\left(D_{s}-2 X\right) \cdot\left(D_{l}-2 X\right) \cdot V_{c}} \frac{K^{2}}{2 X}
$$

If we can assume that $L$ is in proportion to $\left(D_{l}-2 X\right)$ at constant EMS power and that $D_{l}$ is much greater than $D_{s}$ and $X$, Eq. (9) can be rewritten as follows:

$$
\mathcal{N} \propto\left(\begin{array}{c}
D_{l} \\
D_{s}-2 X
\end{array}\right) \cdot\left(\begin{array}{c}
K^{2} \\
V_{c} \cdot X
\end{array}\right)
$$

According to Eq. (10), it can be found that $\mathcal{N}$ increases as $V_{c}$ decreases and $K$ increases following the increase of the secondary spray cooling water, when the distance from the meniscus to the position of EMS is constant. In addition, when the casting speed $\left(V_{c}\right)$ is constant, $\mathcal{N}$ decreases with the increase of slab thickness. Therefore, the results of this experiment can be explained qualitatively by Eq. (10). Figure 9 shows the relation between relative $\mathcal{N}$, estimated by Eq. (10), and the fineness of the network structure. Good relation can be found from this figure.

\section{Conclusion}

(1) The segregation etch print (EP) method can detect and record segregation even in low $\mathrm{S}, \mathrm{Ca}$ added steels rapidly and conveniently over a wide area with high resolving power.

(2) By use of the EP method, the network structure which could not be seen by the ordinary etching method for detecting the solidification structure could be found in the equiaxed crystal zone of CG slabs.

(3) The casting conditions which affect the size of the network structure were casting speed, casting temperature, secondary spray cooling water amount, addition of REM and the thickness of the slab.

(4) The fineness of the network structure is

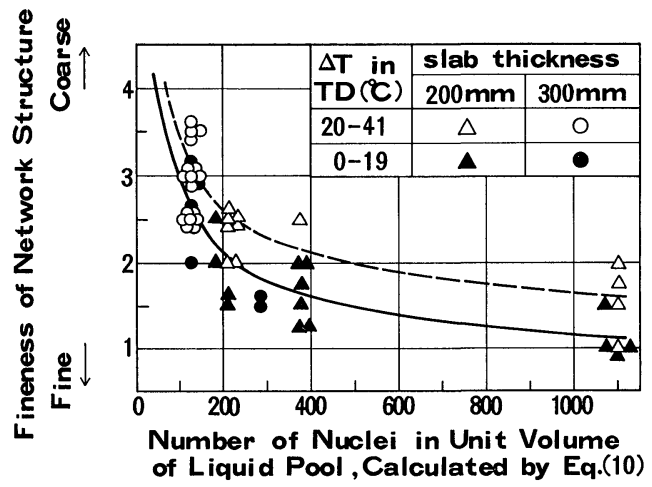

Fig. 9. Relation between the fineness of network structure and $\mathcal{N}$. 


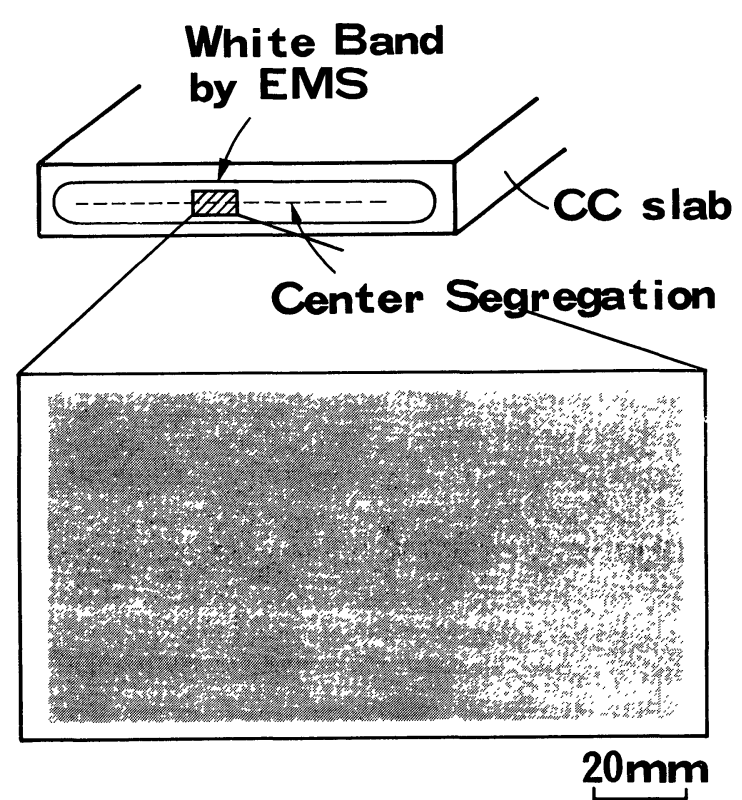

Photo. 11. EP of CC slab cast under the conditions determined by this investigation.

related to the segregation level, and a fine network structure remarkably suppresses even spot-like segregation and $\mathrm{V}$-shaped segregation besides central segregation in CG slabs (Photo. 11).

\section{REFERENCES}

1) S. Kitamura, K. Miyamura, R. Isobe, I. Fukuoka and M. Hirai: Tetsu-to-Hagané, 68 (1982), S217.

2) H. Soga, S. Kawashima, K. Kitamura, K. Sasaki, M. Sato and H. Ishijima: Tetsu-to-Hagané, 67 (1981), S1108.

3) S. Kitamura, K. Miyamura, S. Sakaguchi, K. Kitamura and H. Soga: Tetsu-to-Hagané, 68 (1982), S868.

4) I. Taguchi, H. Hamada and M. Kama: Collected Abstracts of the 1981 Autumn Meeting of Japan Inst. Metals, (1981), 89.

5) S. Kitamura, K. Miyamura, S. Sakaguchi and C. Hamaguchi: Tetsu-to-Hagané, 69 (1983), S264.

6) K. Kawakami: Data of the Council of Solidification Phenomena, Subcommittee 3, the 19th Committee, the Japan Society for the Promotion of Science, (Sept. 1973).

7) Y. Itoh, H. Maeda and C. Okajima: Tetsu-to-Hagané, 62 (1976), S463.

8) H. Takeuchi, H. Mori, Y. Ikehara, T. Komano and T. Yanai: Tetsu-to-Hagané, 66 (1980), 638.

9) Y. Nuri, T. Ohashi, T. Hiromoto and O. Kitamura: Tetsu-to-Hagané, 66 (1980), 618.

10) Y. Nuri, T. Ohashi, T. Hiromoto and O. Kitamura: Tetsu-to-Hagané, 66 (1980), 628.

11) T. Kawawa, H. Sato, S. Miyahara, T. Koyano and H. Nemoto: Tetsu-to-Hagané, 60 (1974), 486.

12) H. Jacobi and K. Schwerdtfeger: Met. Trans., 7A (1976), 811. 